Research Article

\title{
Evaluation of Liposomal Formulations of Quercetin on Promonocytic Human Myeloid Leukemia Cell Line
}

\author{
Shreya Banerjee ${ }^{1,2}$, Debasis Dutta ${ }^{2}$, Shila Elizabeth Besra ${ }^{1^{*}}$ \\ 1.Central Instrumentation Facility and Cancer Biology \& Inflammatory Disorder Division, CSIR- Indian Institute of Chemical Biology, 4 \\ Raja S.C. Mullick Road, Kolkata-700032, West Bengal, India. \\ 2.Pharmaceutics Division, Department of Pharmacy, School of Health Sciences, NSHM Knowledge Campus, Kolkata-Group of \\ Institutions, 124 (60), B. L. Saha Road, Tara Park, Behala, Kolkata -700053, West Bengal, India.
}

*Corresponding author's E-mail: shilabesra@iicb.res.in

Received: 18-09-2020; Revised: 28-11-2020; Accepted: 05-12-2020; Published on: 15-12-2020.

\section{ABSTRACT}

Novel Drug Delivery System is a recent and advanced field of study which can be used to modify the pharmacokinetic and pharmacodynamics properties of a drug. Quercetin is a flavonoid of natural origin known to have anti-cancer and antioxidant properties. It belongs to BCS Class IV and hence challenges are faced to combat the solubility issues of the drug. Therefore, this study aims to preparing a liposomal formulation of Quercetin to improve its solubility profile and thereby intensify its pharmacological activity. Initial characterizations of the prepared Quercetin liposomal formulations (QTLF) were evaluated on promonocytic human myeloid leukemia (U937), cell by MTT assay. QTLF produced notable cytotoxic effect on U937. The Quercetin liposomal formulations showed greater efficacy than the free drug in U937. Thus, it can be considered safe for administration into the human body which proved that the solubility enhancement of drug produced a more potent form of the drug.

Keywords: Novel Drug Delivery, Quercetin, Liposome, Leukemia, Cytotoxicity.

QUICK RESPONSE CODE $\rightarrow$

DOI:

10.47583/ijpsrr.2020.v65i02.012

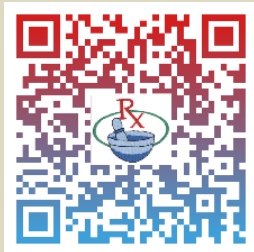

DOI link: http://dx.doi.org/10.47583/ijpsrr.2020.v65i02.012

\section{INTRODUCTION}

$\mathrm{C}$ onventional drug delivery systems have limited efficiency in this medical world of large number of diseases and complications that affect the human body on a regular basis. Hence, the needs for faster and sustainable therapies arise. Novel drug delivery system is an advanced delivery system which appears suitable for fulfilling such requirements. The novel drug delivery system (NDDS) consists of carriers which maintain the drug concentration in therapeutic range for longer period of time and improve the bioavailability ${ }^{1}$. Novel drug delivery follows the method of drug release modification by using modified polymers and also different carriers which release the drug at the site of action. Carriers include nanoparticles, liposomes, phytosomes etc. ${ }^{2}$

Liposomes are a group of novel vesicular systems which can incorporate a variety of drugs of both hydrophobic and hydrophilic natures ${ }^{3}$. They are biocompatible as they resemble the structure of a biological membrane ${ }^{4}$. It primarily consists of phospholipids, which are molecules that have a head group and a tail group. The head is attracted to water, and the tail, which is made of a long hydrocarbon chain, is repelled by water ${ }^{5}$. Researchers all over the world have been working on natural products, keeping in mind the harmful effects of synthetic drugs and have succeeded in establishing their affectivity on various diseases. Flavonoids are a group of natural products which are present in quite a number of fruits and vegetables and can be useful in treating various pathological conditions. Quercetin is one such flavonoid possessing cytotoxic activity ${ }^{6}$. Its pharmacological actions are limited by hydrophobicity, instability in physiological media, poor gastrointestinal dissolution rate and absorption and extensive xenobiotic metabolism at intestines and liver. Hence, its formulation in a suitable delivery system may improve its oral bioavailability, ensuring protection from degradation and preventing premature release ${ }^{7,8}$.

Cancer is the biggest cause of mortality in the world and happens when the tumor suppressing genes are obstructed by various environmental or lifestyle factors ${ }^{9}$. The types of cancer are sarcoma which includes growth of malignant tumours in connective tissues, lymphoma which causes proliferations in lymphocytes, leukaemia which leads to uncontrolled and exaggerated growth of blood cells and sarcoma which results in uncontrolled division of cells in the skin or tissue which cover the internal organs ${ }^{10}$, $11,12,13$. Leukemia being one of the most dangerous types of cancers is associated with serious impact on human body ${ }^{14}$.

So, this study focuses on the development and evaluation of a liposomal formulation (QTLF) of a drug of natural origin named Quercetin and thereby analyzing its activity on human myeloid leukemia cell line U937. 


\section{MATERIALS AND METHODS}

\section{Chemicals}

Quercetin (Loba Chemie, India), Ethanol absolute (Balaji Drugs Pvt. Limited, India), Chloroform (Balaji Drugs Pvt. Limited, India), Soya Lecithin (Himedia, India), Hydrogen Chloride (Rankem , Avantor, India), Potassium chloride, Potassium di-hydrogen phosphate, Sodium hydroxide (Merck Specialties Pvt. Ltd., Mumbai), Distilled water, RPMI1640 medium with L-glutamine (GIBCO), Foetal calf serum (FCS), Penicillin-Streptomycin, Gentamycin, MTT [3(4,5-dimethylthiozol-2-il)

2,5-2,5dipheniltetrazoliumbromide], Dimethyl sulphoxide (DMSO).

\section{Cell Culture}

Human leukemic cell line U937 cell line was obtained from National Centre for Cell Science, Pune for in-vitro studies. These cells were sub-cultured as per the requirement of the experiment at an initial concentration of $1 \times 10^{6}$ cells/ml. U937 cells were maintained in sterile RPMI 1640 medium supplemented with $10 \%$ heat activated FCS and cultures was maintained at $37^{\circ} \mathrm{C}$ in a humified atmosphere containing $5 \% \mathrm{CO}_{2}$ in air.

\section{Preparation of Standard Curve of Quercetin in Ethanol at 370nm}

$50 \mathrm{mg}$ Quercetin was measured and taken into a $50 \mathrm{ml}$ volumetric flask. $50 \mathrm{ml}$ ethanol was added into the flask to solubilise the Quercetin (QTF) properly and concentration becomes $1000 \mu \mathrm{g} / \mathrm{ml}$. $5 \mathrm{ml}$ of solution was taken and dissolved in $50 \mathrm{ml}$ ethanol to make $100 \mu \mathrm{g} / \mathrm{ml}$. From this stock solution different concentrations of QTF solution i.e., $2 \mu \mathrm{g} / \mathrm{ml}, 4 \mu \mathrm{g} / \mathrm{ml}, 6 \mu \mathrm{g} / \mathrm{ml}, 8 \mu \mathrm{g} / \mathrm{ml}$ and $10 \mu \mathrm{g} / \mathrm{ml}$ were prepared using ethanol. The Quercetin solutions were scanned in UV Visible Spectrophotometer (UV 1800, Shimadzu, Japan) at 200-400nm. Then absorbance was measured by UV Spectrophotometry at $370 \mathrm{~nm}$ wavelength using ethanol as blank.

\section{Preparation of Standard Curve of Quercetin in Phosphate buffer pH 7.4 at $370 \mathrm{~nm}$}

$25 \mathrm{mg}$ quercetin was measured and taken in a $100 \mathrm{ml}$ volumetric flask. Around $1 \mathrm{ml}$ of ethanol was added into the flask to solubilise the Quercetin properly and the volume was made up to $100 \mathrm{ml}$ with phosphate buffer solution $\mathrm{pH}$ 7.4 to make a concentration of $250 \mu \mathrm{g} / \mathrm{ml}$. From this stock solution different concentrations of QTF solution $5 \mu \mathrm{g} / \mathrm{ml}$, $10 \mu \mathrm{g} / \mathrm{ml}, 15 \mu \mathrm{g} / \mathrm{ml}, 20 \mu \mathrm{g} / \mathrm{ml}$ and $25 \mu \mathrm{g} / \mathrm{ml}$ were prepared using phosphate buffer $\mathrm{pH}$ 7.4. The quercetin solution was scanned in UV Visible spectrophotometer (UV 1800, Shimadzu, Japan) at 200-400nm. Then absorbance was measured by UV Spectrophotometry at $370 \mathrm{~nm}$ wavelength using phosphate buffer as blank ${ }^{15}$.

\section{Preparation of Liposomal Formulations of Quercetin}

Blank liposomes were prepared using lipid and the organic solvents only and the consistency of the formulation was checked. After that lipid mixture of phospholipid and Quercetin was dissolved in two organic solvents which were present in a fixed ratio and shaken continuously for some time under a temperature of $50-55 \circ$ C. The film formed was then hydrated by an aqueous buffer solution and the dispersion was then sonicated. The liposome dispersion was transferred into a tube and then placed in a bath sonicator. Controlling the temperature of the lipid dispersion is usually easier in this method. The dispersion was then kept in a sterile container and stored for evaluation ${ }^{16}$.

Table 1: Formulations of Liposome Preparation

\begin{tabular}{|c|c|c|c|c|c|c|c|c|}
\hline INGREDIENT & QTLF1 & QTLF2 & QTLF3 & QTLF4 & QTLF5 & QTLF6 & QTLF7 & QTLF8 \\
\hline Quercetin/mg & 80 & 75 & 150 & 270 & 200 & 234 & 270 & 200 \\
\hline Soya Lecithin/mg & 20 & 25 & 20 & 20 & 20 & 20 & 40 & 30 \\
\hline Ethanol/ ml & 10 & 10 & 10 & 10 & 10 & 10 & 10 & 10 \\
\hline Chloroform/ ml & 10 & 10 & 10 & 10 & 10 & 10 & 10 & 10 \\
\hline
\end{tabular}

\section{Drug Identification Study by FTIR}

Fourier Transform Infrared Spectroscopy (FTIR) of pure drug using FTIR spectrophotometer. The sample is prepared with potassium bromide and data are collected at a spectral range of $450-4000 \mathrm{~cm}^{-1} .{ }^{15}$

\section{Entrapment Efficiency (\%EE)}

The mixture was centrifuged for 70 minutes at $14000 \mathrm{rpm}$, the supernatant containing free Quercetin was obtained, and the absorbance was measured using HPLC. The entrapment efficiency of liposomes was determined by the following formula: $\mathrm{EE}(\%)=\left\{\left(C_{i}-C_{f}\right) / C_{i}\right\} \times 100$ where EE is the concentration of entrapped sample $(\mathrm{mg} / \mathrm{mL}), C_{i}$ is the initial concentration of sample used in formulating the liposomes $(\mathrm{mg} / \mathrm{mL}), C_{f}$ is the concentration of sample in the supernatant $(\mathrm{mg} / \mathrm{mL})$, and $E E(\%)$ is the percentage of the sample's entrapment. ${ }^{17}$

\section{Cytotoxicity Study by MTT Assay}

For cytotoxicity analysis, 1 × $10^{5}$ concentrations of human leukemic cell $\mathrm{U} 937$ in log phase were used as stock suspension. $100 \mu$ l of these cell suspensions were seeded in each well of 96 well tissue culture plates. They were treated separately with freshly prepared $1 \mathrm{mg} / \mathrm{ml}$ stock solution of free Quercetin as well as the Liposomal formulations of Quercetin (QTLF1-QTLF8), with doses of $25 \mu \mathrm{g}, 50 \mu \mathrm{g}, 100 \mu \mathrm{g}$ and $200 \mu \mathrm{g}$ for $24,48,72$ hours at $37^{\circ} \mathrm{C}$ in a humified atmosphere containing $5 \% \mathrm{CO}_{2}$ in air. Untreated cells served as control. At the end of treatment, 
$20 \mu \mathrm{l}$ of MTT [3-(4,5-dimethylthiozol-2-il)-2,5-2,5dipheniltetrazoliumbromide] was added to each well and incubated for another 4 hours at 37-degree $\mathrm{C}$ in a $\mathrm{CO}_{2}$ incubator. The MTT assay is a colorimetric assay for measuring the activity of enzymes that reduce MTT to formazan dyes, giving a purple colour. A solubilisation solution DMSO (Dimethyl sulphoxide) $100 \mu \mathrm{l}$ is added to dissolve the insoluble purple formazan product into a coloured solution. The absorbance was taken at $490 \mathrm{~nm}$ by micro plate manager (Reader Type: Model 680 XR Bio-Rad laboratories Inc.). From the absorbance values obtained at $490 \mathrm{~nm}$ the \% inhibition was determined using the relation: \% Cell Inhibition: 100 X (O. D of Control - O. D of Treated)/ O. D of Control ${ }^{18}$.

\section{Statistical Analysis}

This was done by Student's t-test $P<0.05$ was considered as significant. The percentage cell inhibition was calculated by the following formula: \% Cell Inhibition: 100 X (O. D of Control - O. D of Treated)/ O. D of Control Where O. D= Optical Density

\section{RESULTS}

\section{Preparation of Standard Curve of Quercetin in Ethanol at 370nm}

The Quercetin solutions $(2 \mu \mathrm{g} / \mathrm{ml}, 4 \mu \mathrm{g} / \mathrm{ml}, 6 \mu \mathrm{g} / \mathrm{ml}, 8 \mu \mathrm{g} / \mathrm{ml}$ and $10 \mu \mathrm{g} / \mathrm{ml}$ ) dissolved in ethanol were scanned in UV Visible Spectrophotometer (UV 1800, Shimadzu, Japan) at 200-400nm. Then absorbance was measured by UV Spectrophotometry at 370nm wavelength using ethanol as blank. A graph was plotted keeping the concentrations in the $\mathrm{X}$-axis and the absorbance found in the $\mathrm{Y}$-axis.

Table 2: Standard Curve of QTF in Ethanol

\begin{tabular}{|c|c|c|c|c|}
\hline & \multicolumn{3}{|c|}{ Absorbance } & Average \pm S.D. \\
\hline 2 & $\mathbf{1}^{\text {st }}$ & $\mathbf{2}^{\text {nd }}$ & $\mathbf{3}^{\text {rd }}$ & \\
\hline 4 & 0.156 & 0.162 & 0.169 & $0.162 \pm 0.005$ \\
\hline 6 & 0.331 & 0.353 & 0.360 & $0.348 \pm 0.012$ \\
\hline 8 & 0.439 & 0.452 & 0.445 & $0.445 \pm 0.005$ \\
\hline 10 & 0.697 & 0.699 & 0.707 & $0.701 \pm 0.004$ \\
\hline
\end{tabular}

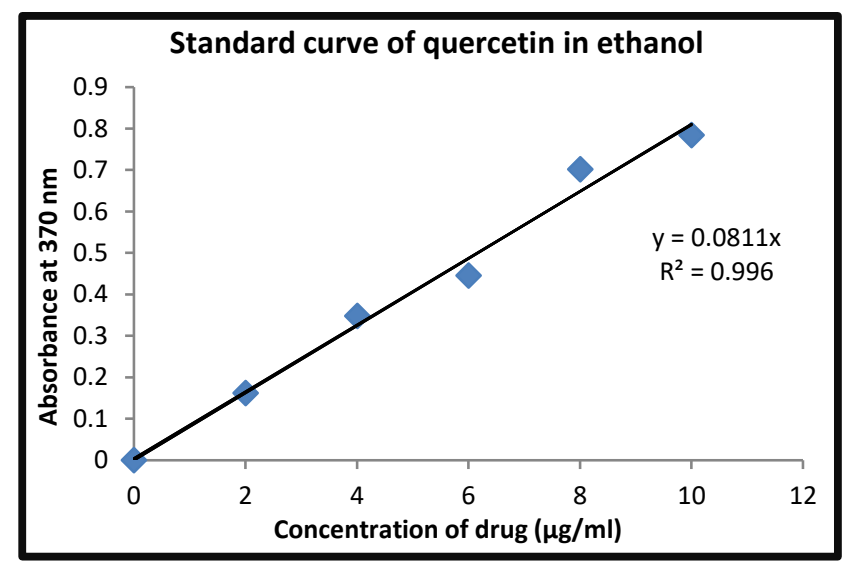

Figure 1: Standard Curve of Quercetin in Ethanol. The concentration is plotted in the $\mathrm{X}$-axis and the Absorbance is plotted in the $\mathrm{Y}$-axis. The graph gives us an $\mathrm{R}^{2}$ value of 0.9875 .

\section{Preparation of Standard Curve of Quercetin in Phosphate buffer pH 7.4 at $370 \mathrm{~nm}$}

The quercetin solution $(5 \mu \mathrm{g} / \mathrm{ml}, 10 \mu \mathrm{g} / \mathrm{ml}, 15 \mu \mathrm{g} / \mathrm{ml}$, $20 \mu \mathrm{g} / \mathrm{ml}$ and $25 \mu \mathrm{g} / \mathrm{ml}$ dissolved in phosphate buffer $\mathrm{pH}$ 7.4) was scanned in UV Visible spectrophotometer (UV 1800, Shimadzu, Japan) at 200-400nm. Then absorbance was measured by UV Spectrophotometry at $370 \mathrm{~nm}$ wavelength using phosphate buffer as blank.

Table 3: Standard Curve of QTF in Phosphate Buffer pH 7.4

\begin{tabular}{|c|c|c|c|c|}
\hline \multirow{2}{*}{ Concentration $(\mu \mathrm{g} / \mathrm{ml})$} & \multicolumn{3}{|c|}{ Absorbance } & Average \pm S.D. \\
\hline 5 & $\mathbf{1}^{\text {st }}$ & $\mathbf{2}^{\text {nd }}$ & $\mathbf{3}^{\text {rd }}$ & \\
\hline 10 & 0.237 & 0.238 & 0.240 & $0.238 \pm 0.0012$ \\
\hline 15 & 0.403 & 0.405 & 0.389 & $0.399 \pm 0.007$ \\
\hline 20 & 0.583 & 0.589 & 0.592 & $0.588 \pm .0037$ \\
\hline 25 & 0.771 & 0.778 & 0.782 & $0.777 \pm .0045$ \\
\hline & 0.996 & 0.994 & 0.993 & $0.994 \pm 0.0012$ \\
\hline
\end{tabular}




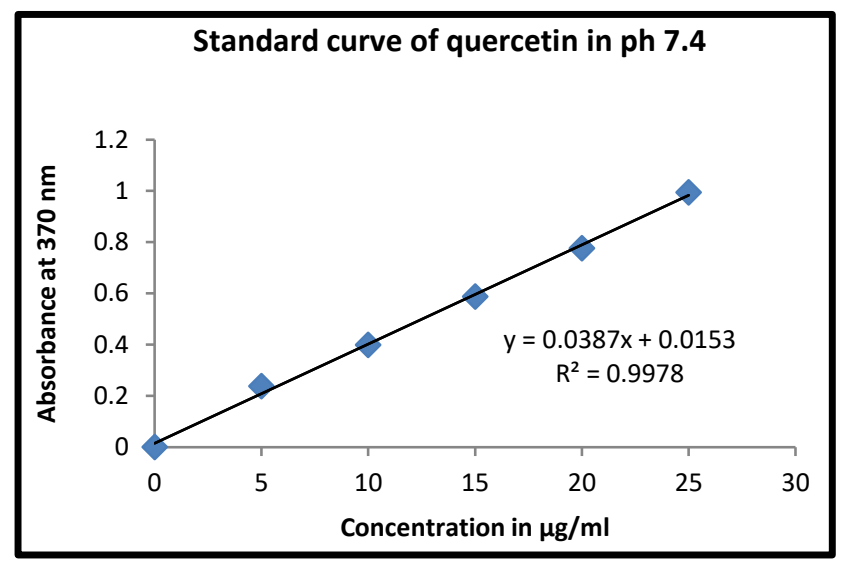

Figure 2: Standard Curve of Quercetin at $\mathrm{pH}$ 7.4. The concentration is plotted in the $\mathrm{X}$-axis and the Absorbance is plotted in the $\mathrm{Y}$-axis. The graph gives us an $\mathrm{R} 2$ value of 0.9978.

\section{Identification of Quercetin by FTIR}

Fourier Transform Infrared Spectroscopy (FTIR) of pure drug was taken using FTIR spectrophotometer. The sample was prepared with potassium bromide and data were collected at a spectral range of $500-4000 \mathrm{~cm}^{-1}$.

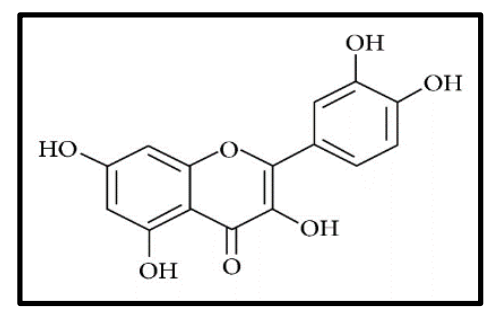

Figure 3: Structure of Quercetin

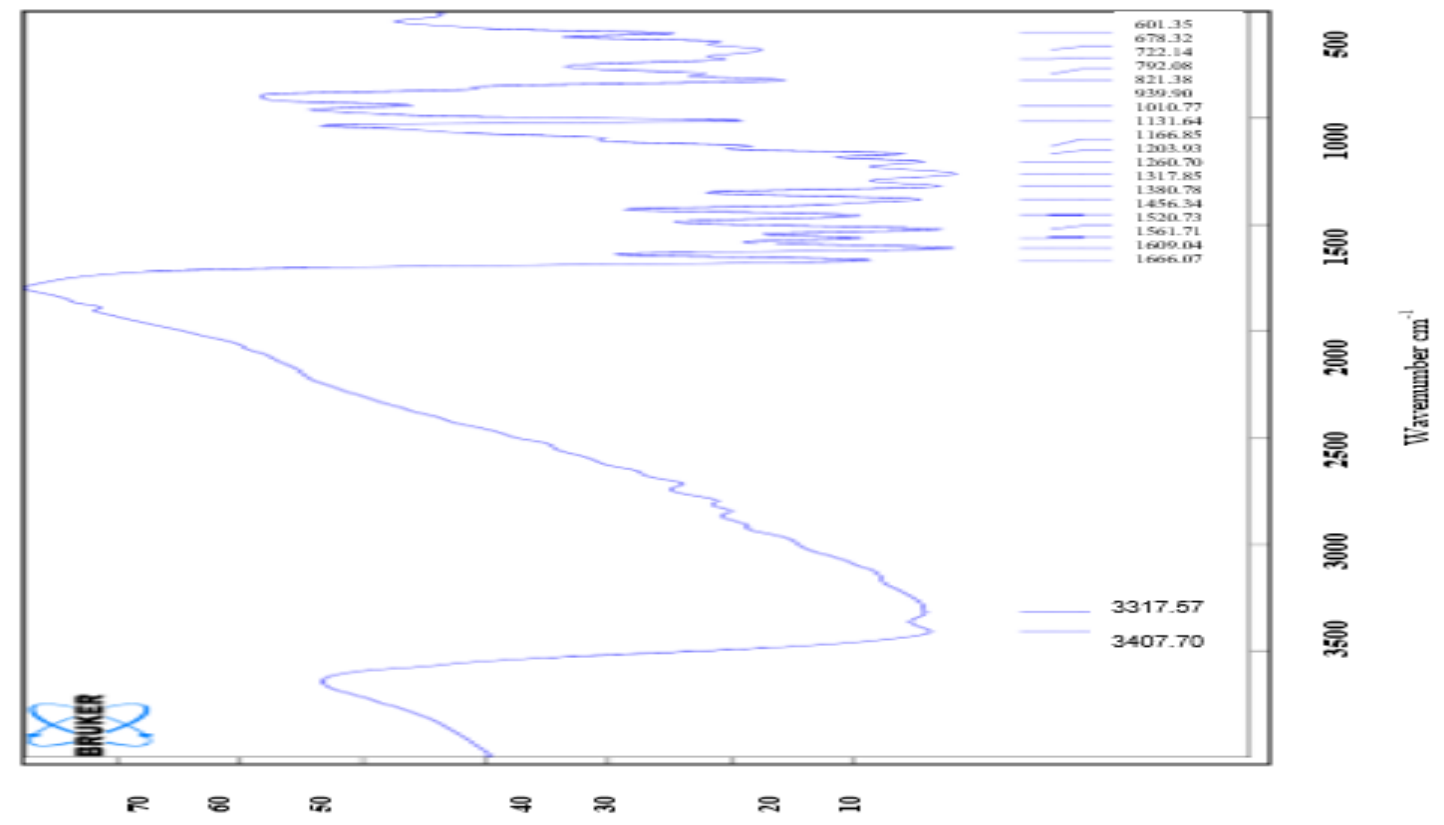

Transmittance \%

Figure 4: FTIR Spectrum of Quercetin

The peaks obtained were at $3407.70 \mathrm{~cm}^{-1}, 3317.57 \mathrm{~cm}^{-1}$, $1666.07 \mathrm{~cm}^{-1}, 1609.04 \mathrm{~cm}^{-1}, 1561.71 \mathrm{~cm}^{-1}, 1520.73 \mathrm{~cm}^{-1}$, $1456.34 \mathrm{~cm}^{-1}, 1380.78 \mathrm{~cm}^{-1}, 1317.85 \mathrm{~cm}^{-1}, 1260.70 \mathrm{~cm}^{-1}$, $1203.93 \mathrm{~cm}^{-1}, 1166.85 \mathrm{~cm}^{-1}, 1131.64 \mathrm{~cm}^{-1}, 1010.77 \mathrm{~cm}^{-1}$, $939.90 \mathrm{~cm}^{-1}, 821.38 \mathrm{~cm}^{-1}, 792.08 \mathrm{~cm}^{-1}, 722.14 \mathrm{~cm}^{-1}$, $678.32 \mathrm{~cm}^{-1}$ and $601.35 \mathrm{~cm}^{-1}$. The peak at $1380.78 \mathrm{~cm}^{-1}$ shows $\mathrm{O}-\mathrm{H}$ bending and that at $3407.70 \mathrm{~cm}^{-1}$ show $\mathrm{O}-\mathrm{H}$ stretching of phenolic groups. The peak at $1520.73 \mathrm{~cm}^{-1}$ points out the presence of aromatic $\mathrm{C}=\mathrm{C}$ stretching and that at $939.90 \mathrm{~cm}^{-1}$ is responsible for aromatic $\mathrm{C}=\mathrm{C}$ bending. The peaks at $1456.34 \mathrm{~cm}^{-1}$ is responsible for inplane aromatic $\mathrm{C}-\mathrm{H}$ bending and at $722.14 \mathrm{~cm}^{-1}$ leads to presence of out of plane bending of aromatic $\mathrm{C}-\mathrm{H}$ bond.
$\mathrm{C}=\mathrm{O}$ stretching is detected by the presence of sharp peak at $1666.07 \mathrm{~cm}^{-1}$.

Entrapment Efficiency: The entrapment efficiency of liposomes was determined by the following formula:

$$
\operatorname{EE}(\%)=\left\{\left(C_{i}-C_{f}\right) / C_{i}\right\} \times 100,
$$

where $\mathrm{EE}$ is the concentration of entrapped sample $(\mathrm{mg} / \mathrm{mL}), C_{i}$ is the initial concentration of sample used in formulating the liposomes $(\mathrm{mg} / \mathrm{mL}), C_{f}$ is the concentration of sample in the supernatant $(\mathrm{mg} / \mathrm{mL})$, and $\mathrm{EE}(\%)$ is the percentage of the sample's entrapment. The entrapment efficiencies were found to decrease with the increase in the amounts of lipid. 
Table 4: Entrapment Efficiency of Quercetin Liposomal Formulation

\begin{tabular}{|c|c|c|c|c|c|}
\hline \multicolumn{3}{|c|}{ Formulation } & \multirow{2}{*}{$\begin{array}{c}\text { Initial Conc. in } \\
\mathrm{mg} / \mathrm{ml}\left(C_{i}\right)\end{array}$} & \multirow{2}{*}{$\begin{array}{c}\text { Final Conc. in } \\
\mathrm{mg} / \mathrm{ml}\left(\mathrm{C}_{\mathrm{f}}\right)\end{array}$} & \multirow[t]{2}{*}{ EE (\%) } \\
\hline Code & Drug (mg) & Lipid (mg) & & & \\
\hline QTLF1 & 20 & 80 & 1.00 & 0.1214 & 87.86 \\
\hline QTLF3 & 20 & 150 & 1.00 & 0.1653 & 83.47 \\
\hline QTLF5 & 20 & 200 & 1.00 & 0.1705 & 82.95 \\
\hline QTLF6 & 20 & 234 & 1.00 & 0.1912 & 80.88 \\
\hline QTLF4 & 20 & 270 & 1.00 & 0.2997 & 70.03 \\
\hline QTLF2 & 25 & 75 & 1.25 & 0.3049 & 75.60 \\
\hline QTLF7 & 40 & 270 & 1.00 & 0.2093 & 79.07 \\
\hline QTLF8 & 30 & 200 & 1.00 & 0.1681 & 83.19 \\
\hline
\end{tabular}

\section{Determination of $\mathrm{IC}_{50}$ values of Quercetin Liposomal Formulations}

$\mathrm{IC}_{50}$ value is the concentration of a drug which inhibits $50 \%$ of the cancer cell growth. This value was determined for the drug QTF as well as the formulations QTLF1-QTLF8. The results for the same are represented in a tabular form as follows:

Table 5: IC 50 Values of the Liposomal Formulations

\begin{tabular}{|c|c|c|c|c|}
\hline SI. No. & Formulation & $24 \mathrm{hrs} I C_{50}$ value $(\mu \mathrm{g} / \mathrm{ml})$ & $48 \mathrm{hrs} I C_{50}$ value $(\mu \mathrm{g} / \mathrm{ml})$ & $72 \mathrm{hrs} I \mathrm{C}_{50}$ value $(\mu \mathrm{g} / \mathrm{ml})$ \\
\hline 1 & QTF & 240 & - & - \\
\hline 2 & QTLF1 & 106.70 & - & - \\
\hline 3 & QTLF2 & 169.32 & - & - \\
\hline 4 & QTLF3 & - & 35.36 & - \\
\hline 5 & QTLF4 & - & 10.41 & - \\
\hline 6 & QTLF5 & - & 175.95 & - \\
\hline 7 & QTLF6 & - & - & 63.45 \\
\hline 8 & QTLF7 & - & - & 51.33 \\
\hline 9 & QTLF8 & - & - & 37.25 \\
\hline
\end{tabular}

\section{Cytotoxicity Study by MTT Assay}

The raw drug (QTF) and the liposomal formulations (QTLF1-QTLF8) inhibited the growth and produced significant cytotoxicity of leukemic cell lines. Reduction in the mean OD of cells treated with increasing dose of drug was observed as compared to control for $24 \mathrm{hrs}, 48 \mathrm{hrs}$ and $72 \mathrm{hrs}$ respectively. The $\%$ inhibitions were also plotted against the increasing concentrations of the formulations. On determining the entrapment efficiency, QTLF1 showed the maximum percentage whereas QTLF4 showed the least value. The formulations (QTLF1-QTLF4) showed a satisfactory activity on $U 937$ cell line after 24 hours which indicates proper effect after 48 or 72 hours of exposure. The liposomal formulations have shown a decrease in $\mathrm{IC}_{50}$ values as compared to the free drug in U937. The I $\mathrm{I}_{50}$ value for free Quercetin was $240 \mu \mathrm{g} / \mathrm{ml}$ whereas the respective $\mathrm{IC}_{50}$ values of formulations QTLF1-QTLF8 were $106.81 \mu \mathrm{g} / \mathrm{ml}, 169.32 \mu \mathrm{g} / \mathrm{ml}$ at 24 hours, $35.36 \mu \mathrm{g} / \mathrm{ml}$, $10.41 \mu \mathrm{g} / \mathrm{ml}, 175.95 \mu \mathrm{g} / \mathrm{ml}$ at 48 hours, $63.45 \mu \mathrm{g} / \mathrm{ml}$, $51.33 \mu \mathrm{g} / \mathrm{ml}$ and $37.25 \mu \mathrm{g} / \mathrm{ml}$ at 72 hours respectively. In U937 cells, formulations QTLF5-QTLF8 were found to show gradual release of Quercetin with negligible action after 24 hours but notable effect after 72 hours of treatment whereas QTLF1-QTLF4 showed cytotoxic action right from the very beginning. This proved that in QTLF5-QTLF8 the lipid matrix had kept Quercetin entrapped for a longer span of time. QTLF1 was found to have the best IC 50 value among all the eight prepared formulations.

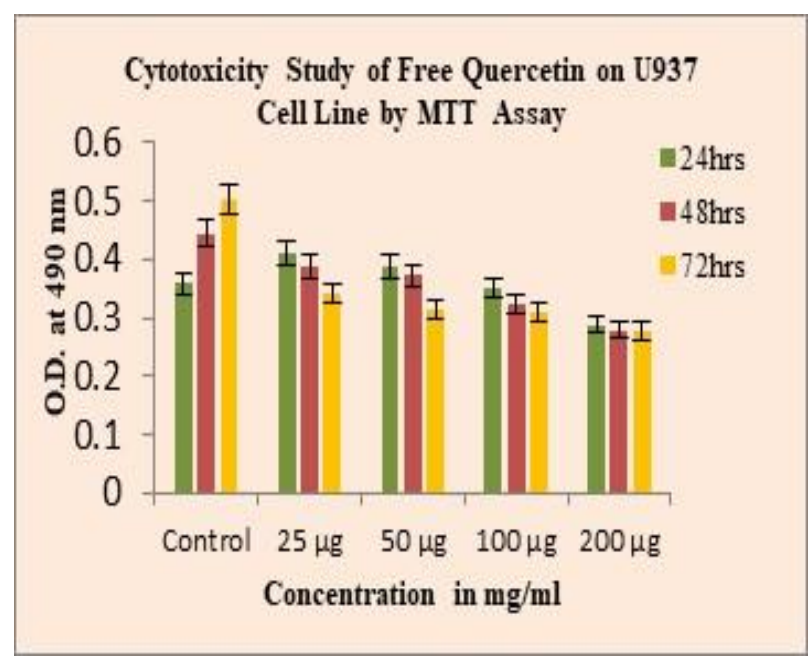




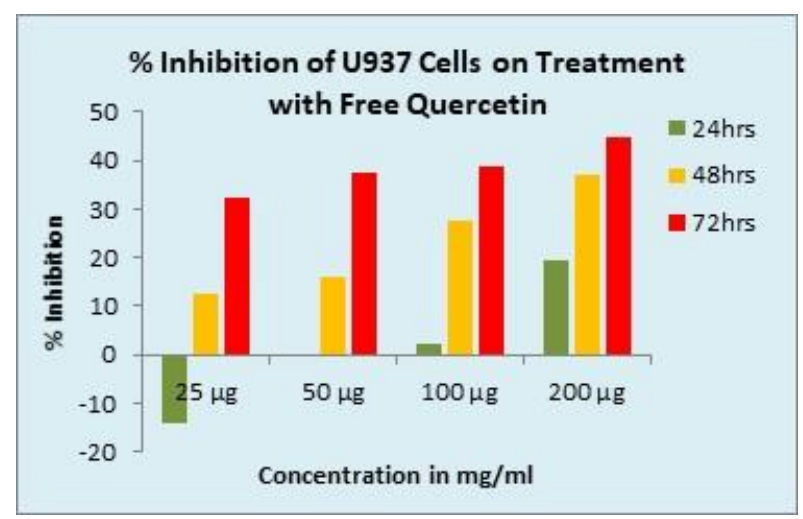

Figure 5: Both the histogram shows the effect of QTF on U937 cell line. Reduction in O.D. value and increase of \% inhibition was observed in a time and concentration dependant manner. Data are mean \pm S.E.M.
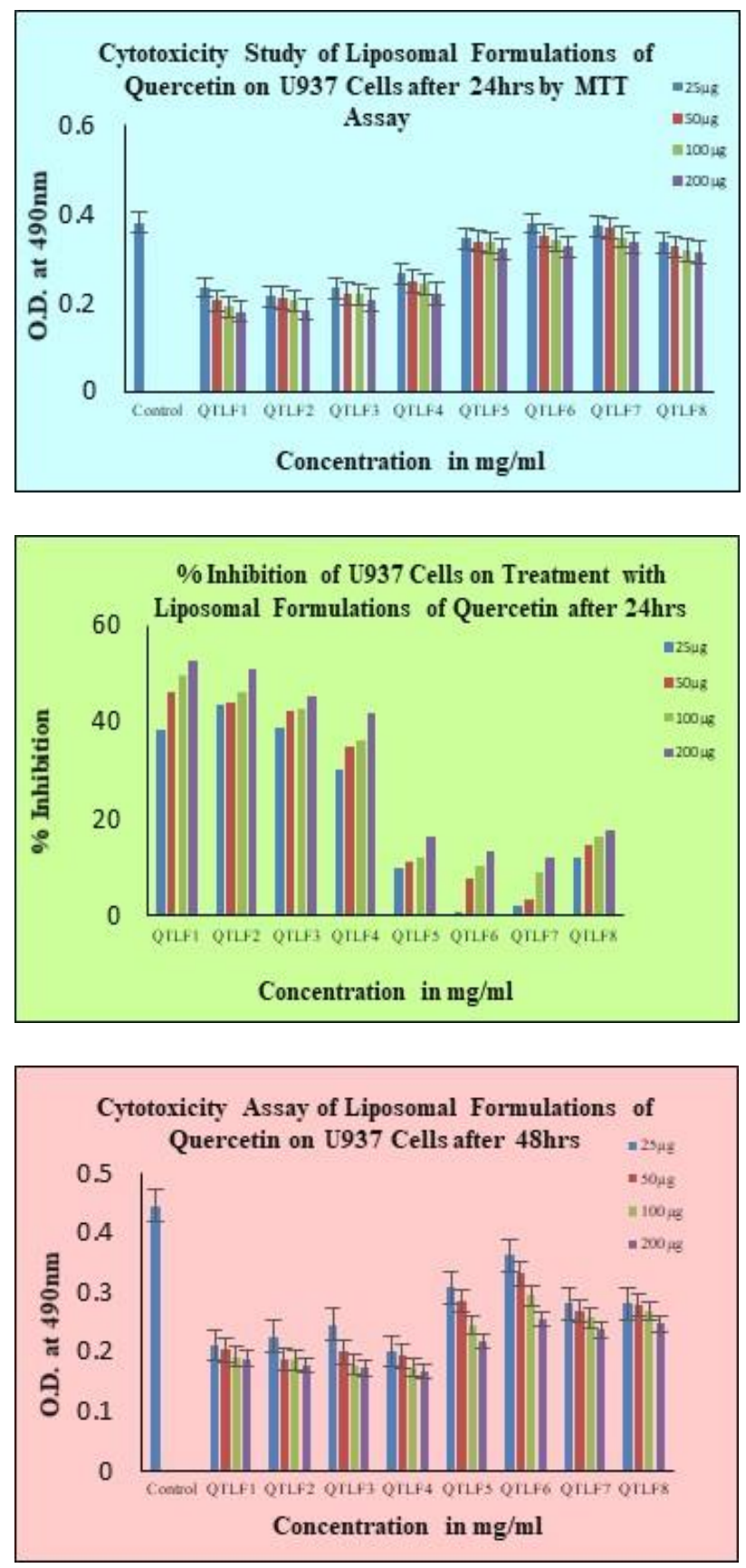
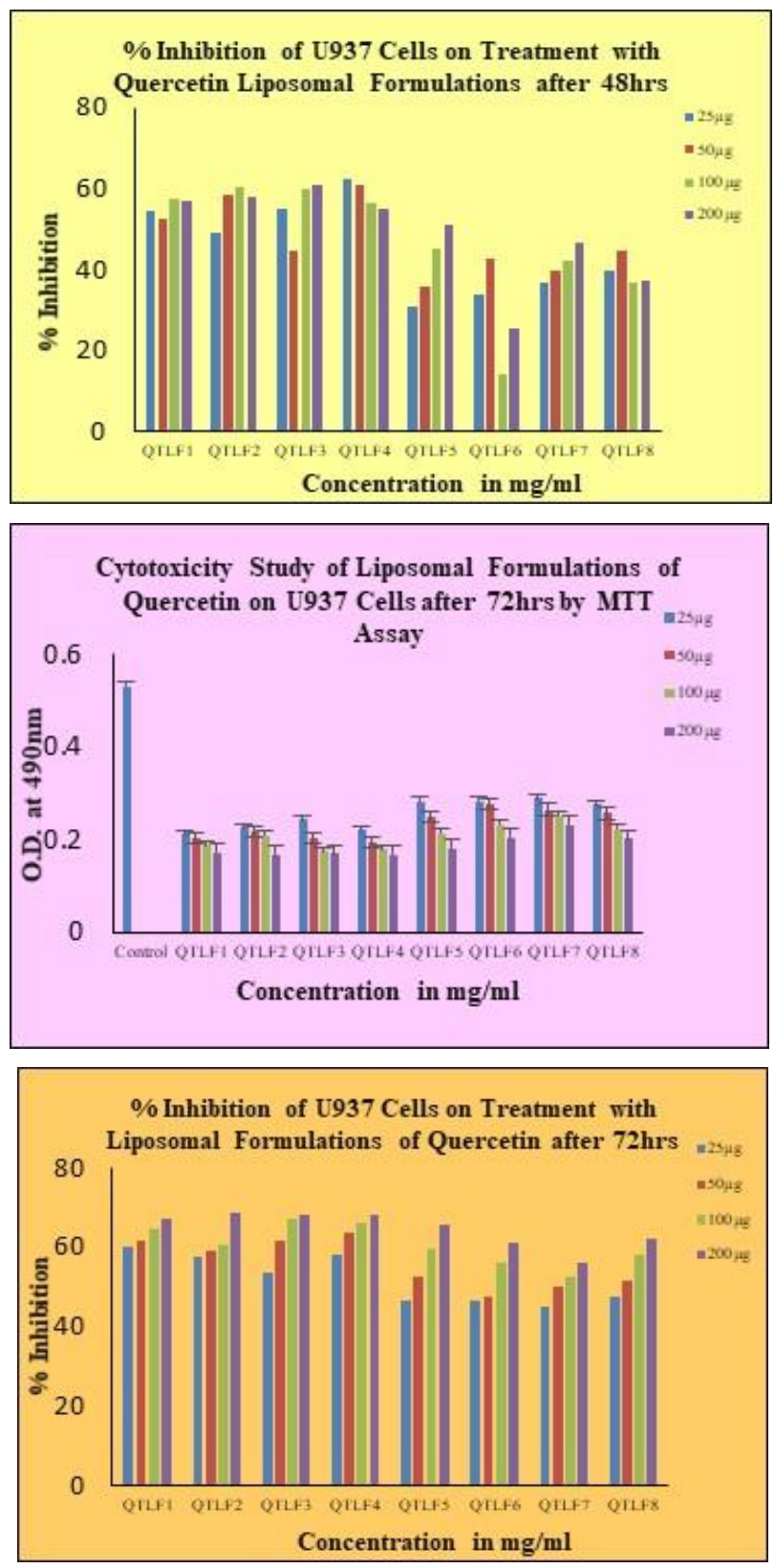

Figure 6: Histograms show the effects of QTLF1-QTLF8 on U937 by MTT Assay after 24, 48 and 72 hours respectively. Reduction in the O.D. values and increase in the \% inhibition of cells is observed in a time and concentration dependant manner. Data are mean \pm S.E.M. QTLF1-QTLF4 shows marked reduction in O.D. value and notable increase in the $\%$ inhibition at $24 \mathrm{hrs}$ whereas QTLF5-QTLF8 show delayed action on both O.D. values and $\%$ inhibition with maximum effect after 72 hours.

\section{DISCUSSION}

Quercetin manifests low solubility which posed a problem in its effectiveness after administration into the body in spite of having strong anti-cancer and antioxidant properties ${ }^{4}$. Liposomes are novel carriers which are known to increase bioavailability of hydrophilic as well as lipophilic components, thereby making Quercetin a proper candidate for incorporation into it ${ }^{2}$. Cancer being one of the biggest causes of mortality is a huge threat to mankind and as a result continuous efforts are being given on 
development of anti-cancer drugs and formulations. About $60 \%$ of drugs currently used for cancer treatment have been isolated from natural products, majorly from plant sources due to efficacy and reduced side effects ${ }^{19}$. Quercetin is a naturally occurring flavonoid which has been used in cancer prevention and to prevent the spread of various cancers, such as lung, prostate, liver, breast, colon, and cervical cancers ${ }^{20}$. This study thereby deals with the tackling of the solubility issues of Quercetin by incorporating it into liposomes and determination of its anti-cancer activities.

On determining the entrapment efficiency, QTLF1 showed the maximum percentage whereas QTLF4 showed the least value. The cytotoxic activity was observed in $U 937$ cell line isolated from the histolytic lymphoma of a 37year-old male patient. The liposomal formulations have shown a decrease in $\mathrm{IC}_{50}$ values as compared to the free drug in U937. The $I_{50}$ value for free Quercetin was $240 \mu \mathrm{g} / \mathrm{ml}$ whereas the respective $I_{50}$ values of formulations QTLF1-QTLF8 were $106.81 \mu \mathrm{g} / \mathrm{ml}$, $169.32 \mu \mathrm{g} / \mathrm{ml}$ at 24 hours, $35.36 \mu \mathrm{g} / \mathrm{ml}, 10.41 \mu \mathrm{g} / \mathrm{ml}$, $175.95 \mu \mathrm{g} / \mathrm{ml}$ at 48 hours, $63.45 \mu \mathrm{g} / \mathrm{ml}, 51.33 \mu \mathrm{g} / \mathrm{ml}$ and $37.25 \mu \mathrm{g} / \mathrm{ml}$ at 72 hours respectively. In U937 cells, formulations QTLF5-QTLF8 were found to show gradual release of Quercetin with negligible action after 24 hours but notable effect after 72 hours of treatment whereas QTLF1-QTLF4 showed cytotoxic action right from the very beginning. This proved that in QTLF5-QTLF8 the lipid matrix had kept Quercetin entrapped for a longer span of time. QTLF1 was found to have the best $I_{50}$ value among all the eight prepared formulations.

\section{SUMMARY \& CONCLUSION}

Natural products are of prime importance in the pharmaceutical industries in the current scenario where synthetic drugs have considerable amounts of adverse effects which affect mankind. A wide number of natural drug products are currently under study for their respective pharmacological uses. One such group of active natural products are the flavonoids. Flavonoids are polyphenolic plant extracts present in the daily diet and contribute to the flavour and colour of fruits and vegetables. Quercetin is a flavonoid which bears high antioxidant and cytotoxic activity which can be of much use to fight the battle against the most feared disease of the current century, cancer. However, it belongs to BCS Class IV with solubility and permeability limitations which hamper the effectiveness of the drug. This establishes a need to modify the drug's solubility by using carriers.

Novel Drug Delivery is a unique approach for preparing drug formulations with better bioavailability and release at the preferred site of action. Novel drug delivery formulations can be prepared by modifying the release kinetics of drug in the body by incorporation into lipid matrices or in suitable polymers. There are quite a number of novel carriers which are in use for creating new formulations of drugs like liposomes, nanoparticles, phytosomes etc. Novel formulations of some drugs like doxorubicin, amphotericin B are already in market, showing good amount of patient compliance. Similarly, the drug Quercetin was considered a good candidate to be converted into a novel formulation by incorporation into a lipid carrier. The choice of novel carrier was Liposome, a lipid matrix composed of phospholipids with a hydrophilic head and a lipophilic tail. Liposomes represent the biological membranes as far as the structure is considered, and as a result is highly compatible for administration into the body. It has another advantage of being able to incorporate both lipophilic and hydrophilic drugs into it, thereby becoming the carrier of choice for the study.

Cancer is a disease characterized by abnormal cell growth and proliferation leading to some serious health hazards. This occurs by various factors like gene mutations, smoking, environmental factors etc. This study focuses on two of the various types of cancer namely leukaemia and ovarian cancer. Leukaemia is a type of cancer characterized by increased number of white blood cells. Synthetic anti-cancer drugs have been proved to be effective for the treatment but alongside the drugs were found to show serious side effects. Hence, approaches were made to increase natural drug formulations in market which can be equally effective but with reduced side effects.

The free drug Quercetin had to undergo initial identification tests wherein standard curves were prepared and FTIR spectra of the drug was analysed. Eight liposomal formulations of Quercetin within different drug and lipid ratios were prepared by hand shaking method and stored for characterization. The entrapment efficiencies of the formulations were determined. The prepared liposomes were then used for in-vitro studies to check the cytotoxic activities on two types of cancer cells namely the monocytic myeloid leukaemia cell (U937).

Hence, it can be concluded that the liposomal preparations of Quercetin showed better cytotoxic activity on U937 cells as compared to free Quercetin showing lower $\mathrm{IC}_{50}$ values. It thereby possesses anti-leukemic activity. A further conclusion can be drawn that by incorporating the drug into the lipid carrier, the activity of the drug was found to improve and hence the solubility enhancement effectively intensifies the cytotoxic activities of Quercetin by correcting the solubility issues.

Acknowledgement: The authors of this paper are very much thankful to Council of Scientific and Industrial Research, Indian Institute of Chemical Biology (CSIR-IICB), Kolkata for providing the funding to perform the research work and also NSHM Knowledge Campus, Kolkata-Group of Institutions, where a portion of the study was conducted. 


\section{REFERENCES}

1. Khan Mohd. Gayoor., The novel drug delivery system. World Journal of Pharmacy and Pharmaceutical Sciences, 6(7), 2019, 477-487.

2. Kotturi Nagashree., Novel Drug Delivery System. Journal of Pharmaceutics and Nanotechnology, 3(2), 2015, 33-36.

3. Guo Yu, Shen Li-xian, Lu Yan-feng, Li Hai-yan, Min Ke, Li1Lanfang, Yu Cui-yun, Zheng Xing., Preparation of Rutin-liposome Drug Delivery Systems and Evaluation on Their in vitro Antioxidant Activity; Chinese Herbal Medicines, 8(4), 2016, 371-375.

4. BaiJ.,Yanga E., Changa Pahn-Shick, Ryu Sangryeol., Preparation and characterization of endolysin-containing liposomes and evaluation of their antimicrobial activities against gram-negative bacteria. Enzyme and Microbial Technology, 128, 2019, 40-48.

5. Daraee Hadis,, Etemadi Ali, Kouhi Mohammad, Alimirzalu Samira \& Akbarzadeh Abolfazl., Application of liposomes in medicine and drug delivery. Artificial Cells, Nanomedicine, and Biotechnology, 44, 2014, 381-391.

6. Toniazzo Taise, Peres Marina S., Ramos Ana Paula, PinhoSamantha C., Encapsulation of quercetin in liposomes by ethanol injection and physicochemical characterization of dispersions and lyophilized vesicles. Food Bioscience, 19, 2017, 17-25.

7. Caddeoa Carla, Gabrieleb Morena, Fernàndez-Busquetscd Xavier, Valentia Donatella, Faddaa Anna Maria, Puccib Laura, Manconia Maria., Antioxidant activity of quercetin in Eudragit-coated liposomes for intestinal delivery. International Journal of Pharmaceutics, 565, 2019, 64-69.

8. Khor Chia Miang, Ng Wai Kiong, ChanKok Ping, DongYuancai., Preparation and characterization of quercetin/dietary fiber nano formulations. Elsevier, 161, 2017, 109-117.

9. Dutta S., Mahalanobish S., Saha S, Ghosh S., Sil P.C. Natural Products: An upcoming approach to Cancer. Food and Chemical Toxicology, 128, 2019, 240-255.
10. Gao Peng, Seebacher Nicole A., Hornicek Francis, Guo Zheng, Duan Zhenfeng, Advances in Sarcoma Gene Mutations and Therapeutic Targets. Cancer Treatment Reviews, 2018,62: 98-109.

11. Kojo S.J. Elenitoba-Johnson, Megan S. Lim, New Insights into Lymphoma Pathogenesis.Annual review of Pathology: Mechanism of Disease, 9, 2017, 1-25.

12. Nelson Hamerschlak, Leukemia: genetics and prognostic factors. Journal de Pediatria, 84, 2008, 52-57.

13. Dey Biplab, Kumar Arun, A Review Article on Breast Cancer. International Journal of Pharmacy and Pharmaceutical Research, 11(2), 2018, 284-298.

14. Hwang Dongwon, Kim Minsun, Park Hyejin, Jeong Myung In, Jung Woojinand Kim Bonglee., Natural Products and Acute Myeloid Leukemia: A Review Highlighting Mechanisms of Action. Nutrients, 11, 2019, 1010.

15. N. Kendre Prakash, V. Pande Vishal and M. Chavan Kishori, Novel Formulation Strategy to Enhance Solubility of Quercetin. Pharmacophore, 5 (3), 2014, 358-370.

16. R. P. Rao Monica and S. Babrekar Laxmi, Liposomal Drug Delivery for Solubility and Bioavailability Enhancement of Efavirenz. Indian J Pharm Sci. 80(6), 2018, 1115-1124.

17. Sabeti Bahareh, Noordin Mohamed Ibrahim, Shaharuddin, Development and Characterization Sof Liposomal Doxorubicin Hydrochloride with Palm Oil. Bio Med Research International, 2, 2014, 765426.

18. Subhadeep Roy, Nilanjana Deb, Santanu Basu, Shila Elizabeth Besra, "Apoptotic activity of ethanolic extract of Moringa oleifera root bark on human myeloid leukemia cells via activation of caspase cascade" World Journal of Pharmacy and Pharmaceutical Sciences, 2014, 3 (10), 11381156.

19. Dave Shreya, Modi HA and Jain NK., Assessment of anticancer properties of few medicinal plants. Journal of Pharmacognosy and Phytochemistry, 2016, 5(4), 46-52.

20. Xu Dong, Hu Meng-Jiao, Wang Yan-Qiu and Cui Yuan-Lu., Antioxidant Activities of Quercetin and Its Complexes for Medicinal Application. Molecules, 24, 2019, 1123.

\section{Source of Support: None declared.}

Conflict of Interest: None declared.

For any question relates to this article, please reach us at: editor@globalresearchonline.net

New manuscripts for publication can be submitted at: submit@globalresearchonline.net and submit_ijpsrr@rediffmail.com 